\title{
Quantification of interdependencies between economic systems and ecosystem services: An input-output model applied to the Seine estuary
}

\author{
Mateo Cordier ${ }^{\mathbf{a}, \mathbf{c}, *}$, José A. Pérez Agúndez ${ }^{\mathbf{b}}$, Martin O'Connor ${ }^{\mathbf{c}}$, Sébastien Rochette ${ }^{\mathbf{d}}$ \\ and Walter $\mathrm{Hecq}^{\mathrm{a}}$
}

\begin{abstract}
${ }^{\text {a }}$ Centre d'Etudes Economiques et Sociales de l'Environnement/Centre Emile Bernheim, Université Libre de Bruxelles, Université d'Europe, 44 avenue Jeanne, CP. 124, 1050 Bruxelles, Belgium

${ }^{\mathrm{b}}$ Institut Français de Recherche pour l'Exploitation de la Mer (Ifremer)/UMR-Amure/Département d'économie maritime, Centre de Brest, Technopôle de Brest-Iroise, BP 70, 29280, Plouzané, France

${ }^{c}$ Recherches en Economie-Ecologie, Eco-innovation et ingénierie du Développement Soutenable à l'Université de Versailles Saint-Quentin-en-Yvelines (REEDS-UVSQ), 47 boulevard Vauban, Guyancourt 78047 cedex, France

d Université Européenne de Bretagne, UMR 985 Agrocampus OUEST, INRA «Ecologie et Santé des Ecosystèmes», Ecologie halieutique, Agrocampus OUEST, 65 rue de St Brieuc, CS 84215, 35042 Rennes, France

*: Corresponding author : Mateo Cordier, Tel. : + 3226503588 ; fax : + 3226504691 ; email address : mcordier@ulb.ac.be
\end{abstract}

\begin{abstract}
:
The aim of this paper is to assess the possible contribution of an input-output model towards two of the basic principles of the sustainability strategy of integrated coastal zone management (ICZM) and Post-Normal Science. According to these principles, decision-support tools should offer a holistic perspective and handle high uncertainty. The difficulties in reaching sustainability are due partly to the prevailing use of "narrow-system-boundary" tools that are non-holistic. Consequently, they fail to capture important ecosystem services and ignore interdependencies between them. To comply with the basic principles, our method allows environmental assets to be evaluated in multiple units and integrates results from recent researches in natural sciences. Both enable coverage of interdependencies between ecosystem services. Thereby, we enlarge input-output modelling from the two conventional ecosystem services of sink and provisioning to the most vital ones: the supporting services. An application to the Seine estuary addresses the impacts of maritime transportation infrastructures on nursery habitats for commercial fish. The ecosystem services covered are life support and resource provisioning. Our results show that the restoration of a total of $73.7 \mathrm{~km}^{2}$ of nursery areas over the period 2004-2015 would result in a stock of sole in 2015 that exceeds the "business as usual" scenario by $44.2 \%$ (uncertainty range: $35.9 \%-69.9 \%)$. In spite of high restoration costs, the negative macro-economic impact is very low. However, on the sector level, a trade-off results between nurseries and three economic sectors. The quantification of such trade-offs in our model is particularly useful to public participation in decision-making.
\end{abstract}

Highlights $>$ We built a regional input-output model and coupled it to external biological equations describing fish stock and habitats. We enlarged input-output modelling from sink and provisioning services towards the most vital category: supporting services. Results show that nursery restoration generates economic impacts on the sector level rather than on the macro-economic one. This suggests that restoration costs can be seen more as a problem of cost allocation than as a problem per se.

Keywords : Input-output; Ecosystem services; Participative process; Integrated coastal zone management; Post-Normal Science; Decision-support 


\section{Introduction}

The European guidelines for the implementation of the Water Framework Directive recommend the use of cost-benefit analysis (CBA) to identify water bodies in which environmental measures present disproportionate costs (European communities, 2009). For water bodies where costs exceed benefits, decision makers can ask the European Commission to postpone environmental targets or make them less stringent. The European Commission will have to consider such requests carefully as it seems that the difficulties in reaching sustainability are due partly to the prevailing use of - narrw-systemboundary" tools (e.g. CBA). Such tools are useful but they are not the panacea, because they are nonholistic, non-participative and exclude complex environmental issues with too high uncertainty. They represent only one kind of tool among others and should be complemented by other tools and approaches. This has been the problem of the recent decades. Narrow-system-boundary" tools came in support of sector-related and individual resource-based policies in environmental management. As a result, environmental impacts have been analysed separately, whereas holistic analyses were required, as with European coastal zones (Stojanovic and Ballinger, 2009; O'Hagan and Ballinger, 2009; Belfiore, 2000). Consequently, numerous efforts have failed to achieve sustainability.

The prevailing use of farrow-system-boundary" tools such as CBA is partly responsible for the failure to achieve sustainability in European coastal zones. Many investigations on CBA limitations might explain this issue (inter alia van den Bergh, 2000; Maréchal, 2007; Munda et al., 1994). One limitation is that CBA is an analytical approach rather than a holistic one (Ackerman, 2004; Gallopin et al., 2001; Stirling, 2001). That is to say, it considers a narrow range of causes and consequences and takes into account only a small part of the world. It restricts the scope of issues to a micro-scale and leaves out connections. Consequently, CBA fails to consider interdependencies between ecosystem services. However, interdependencies are important (de Groot et al., 2002), since the ecosystem services that directly benefit human activities and survival - resources provisioning and cultural services - depend on the existence of three vital ecosystem services: supporting, regulating and sink services (Millennium Ecosystem Assessment, 2005).

Failing to consider interdependencies is a limitation which is not only inherent in CBA but to all other approaches that use single indicators - e.g. green GDP, genuine saving, ecological footprint, costbenefit ratio in CBA, etc. Single indicators cannot encapsulate all the complexity inherent in ecosystems (Ashford,1981). To solve that problem, Post-Normal Science and Integrated Coastal Zone Management (ICZM) (Box 1) put at their core the basic idea of extended peer communities (i.e. stakeholder participation) to encompass the multiplicity of legitimate perspectives (Funtowicz and Ravetz, 1994; Ravetz, 2006; Stojanovic and Ballinger, 2009 ; Belfiore, 2000 ; O'Hagan and Ballinger, 2009). They recommend avoiding the hegemonization of a single indicator in analyses of environmental issues and suggest complementing single indicator methods with tools that offer holistic properties (Giampietro et al., 2006). This would enable a globalizing approach where various elements, usually dissected into parts, are instead gathered to be studied together with their interactions inside a system (Gallopin et al., 2001). 
Box 1. Post-Normal Science and Integrated coastal zone management.

\section{Post-Normal Science}

Post-Normal Science evolved from a criticism of Probabilistic Risk Analysis. This scientific field attempted to apply standard mathematical methods to problems where the uncertainties were actually overwhelming. The Probabilistic Risk Assessments enjoyed an initial plausibility because they were presented as Science, that is objective and certain, free from bias and doubt. The policy agenda was clear: a risk of one-in-a-million is acceptable. Hence an installation with such a risk is scientifically proved to be safe. However, not all problems with a scientific appearance are capable of solution in orthodox scientific terms (Ravetz, 2006). There exist some problems which are in principle not reducible to "puzzle-solving" normal science in Kuhn's terminology (Kuhn, 1962). Economics applied to environmental issues does not possess the same degree of control of uncertainties as, say, analytical chemistry (Funtowicz and Ravetz, 1994). The new problems of ecological economics faced in this third millennium (e.g. climate change, genetically modified organisms) imply that very often scientists cannot provide any useful input to the social debate without interacting with the rest of the society (i.e. stakeholder participation). These new problems call for a Post-Normal Science (Giampietro et al., 2006; Funtowicz and Ravetz, 1994).

Giampietro et al. (2006) and Funtowicz and Ravetz (1994) illustrate the need for interaction between scientists and the rest of society with the example of the surgeon. The possible outcomes of a surgical operation are not completely determined by scientific facts. In this situation, the patient must have a say in the choices of the surgeon since its choices will determine the final outcome and imply rather important stakes (e.g. possible physical incapacity) and uncertainty (e.g. the surgeon is not sure of the level of incapacity). When uncertainty or stakes are even higher and affect not only a patient but also the rest of society, inferences will be conditioned by the values held by numerous stakeholder groups. In such situations, partisan discussion and a defensive tactic will involve challenging every step of a scientific argument by taking sides (e.g. denial of the existence of the global warming by petrochemical firms). We are now in the realm of Post-Normal Science (Giampietro et al.; 2006).

\section{Integrated Coastal Zone Management (ICZM)}

The practice of integrated management extends back at least to 1965 with the first integrated coastal management program by the San Francisco Bay Conservation and Development Commission. But it spread progressively all over the world and in 2002, 145 countries and semi-sovereign states had initiated integrated coastal zone management efforts (Sorensen, 2002). In Europe, it started in 1992 with the Convention for the Protection of the marine Environment of the North-East Atlantic (the "OSPAR Convention »). This was followed by 35 demonstration projects implemented between 1996 and 1999 in European coastal zones which set the basis for the implementation of ICZM in the European Union (Shipman and Stojanovic, 2007; Belfiore, 2000).

ICZM reflects the movement towards a broader, more holistic perspective from more sectoral and individual resource-based approaches (O'Hagan and Ballinger, 2009; Cheong, 2008). ICZM consists in a strategy that encompasses the whole process of data collection, planning, decision making, implementation management and follow-up. It seeks to achieve sustainability by setting into practice an "integrated" approach to planning and management of human activities. The term "integrated" corresponds to bringing together the components of five main areas inside a single strategy: intersectoral integration, intergovernmental integration, spatial integration (land-ocean integration), interregional and international integration (transboundary issues), and science-management integration (Cheong, 2008). Such a strategy must involve all stakeholders in a participative way (Stojanovic and Ballinger, 2009 ; Belfiore, 2000 ; O'Hagan and Ballinger, 2009).

However, if the advantage of holistic tools is to reflect ecosystem complexity in a better way, the disadvantage is that complexity causes high degrees of uncertainty in turn (Munda et al., 2004; Gallopin et al., 2001). The degree of uncertainty is so high that it often takes the form of -indterminacy", which means that it is impossible to perform an accurate prediction of the future state of the system. That is to say, no statistical correlation can be established between a cause and an effect. As a result, statistic and probability theory do not apply (Giampietro et al., 2006). This is usually due to the inherent ecosystem complexity, the lack of scientific knowledge and the absence of good data. Consequently, some scientists might be tempted to exclude issues from their analysis that are too uncertain. However, addressing issues with indeterminacy is important because high uncertainty is rather a rule than an exception in environmental issues (Munda et al., 1994; Refsgaard, 2006; Stirling, 2001; Giampietro et al., 2006). 
To prevent scientists from putting aside issues with indeterminacy, Post-Normal Science and ICZM suggest an approach that allows high uncertainty to be handled. It consists in using decision-support tools within a stakeholder participation process (Stojanovic and Ballinger, 2009; Belfiore, 2000 ; O'Hagan and Ballinger, 2009). The recognition of the importance of stakeholder participation stems from the strong belief in Post-Normal Science that it is impossible to define in absolute terms what should be considered as enough scientific evidence to make a decision. Inherent ecosystem complexity and our limited understanding mentioned above explain why data and knowledge will always be incomplete (Munda et al., 2004; Gallopin et al., 2001). For instance, in many environmental issues, scientists encounter difficulties in distinguishing the contribution of each cause to an effect or even in considering the multiple effects of one cause (Maxim et al., 2009, Gobin et al., 2004; Refsgaard et al., 2006). Moreover, even when the -case-effect" relationship can be quantified reliably, the individual appraisal of impacts caused by policy measures is inherently subjective (Stirling, 2001). As a result, a part of individual judgment and common sense will always remain. Consequently, the transparent inclusion of divergent public perspectives and value judgment is important. Interesting techniques in this sense are -social multi-criteria evaluations" addressed by Giampietro et al. (2006) and Stirling (2006). This approach consists in a multi-criteria evaluation - in which stakeholders give scores to policy options - combined with a quality assurance to guarantee the reliability of the final result.

The purpose of this paper is to build on the methodological developments from Leontief (1970), Victor (1972), Carpentier (1994) and Jin et al. (2003), with the aim of developing an Input-Output (IO) model based on commodity-by-industry tables and assess the contribution the model can bring to the two basic principles of Post-Normal Science and ICZM. The two basic principles consist in developing methodological approaches for the analysis of environmental issues that i) allow high uncertainty issues to be addressed (Funtowicz and Ravetz, 1994) and ii) demonstrate holistic properties (Giampietro et al., 2006; O'Hagan and Ballinger, 2009; Cheong, 2008) which take into account interdependencies between ecosystem services. With these aims in mind, we have developed an ecological-economic I-O model enabling the identification and quantification of trade-offs (e.g. between environmental and economic targets, between two economic sectors, etc.). The model has been applied to a real case study: the restoration of estuarine nurseries for sole juveniles in the Seine estuary (Haute-Normandie region, France), which is located in the Eastern channel (fishing zone VIId extending from the South of England to North of France). The interdependency between a provisioning ecosystem service (fish resources) and a life supporting service (nursery habitat for fish juveniles) is considered as well as its impact on human activities. Thereby, this paper contributes to extending I-O modelling from the conventional ecosystem services of sink (accumulation of pollutants emitted into the ecosystem) and provisioning (consumption of natural resources) to supporting ecosystem services, the most vital category, since all ecosystem services depend on them (Millennium Ecosystem Assessment, 2005; de Groot et al., 2002).

The remainder of the paper is organized as follows. Section 2 describes the conceptual model of the ecological-economic system analysed in this study. Section 3 formalises the ecological-economic I-O model developed to simulate the system. Data collection is discussed in Section 4. The next two sections apply the model to three policy scenarios of nursery restoration programmes (Section 5) and provide results and discussion on the limitations (Section 6). The final section concludes with the contributions of our model to I-O modelling and to the basic principles of ICZM and Post-Normal Science.

\section{The conceptual model of the ecological-economic system}

The ecological-economic I-O model developed in this paper is built on a conceptual model of the Seine estuary which shows the interrelations between human activities, interdependencies between ecosystem services and interactions between both. It has been designed along with stakeholders through a participative process directed by AESN-DIREN Haute-Normandie (2004). This follows the recommendations from Giampietro et al. (2006) advocating the participation of stakeholders not only 
in the final assessment but also from the very beginning, i.e. in the construction of the problem, the choice of indicators, the selection of data to feed the model, etc.

Within the conceptual model, we have selected the impact of harbour infrastructures on nursery habitats to illustrate the potentialities of ecological-economic I-O modelling. Nurseries are made of estuarine mud- and sand-flats and provide a supporting ecosystem service in the form of habitats which ensure the life of several fish species. In spite of the fact that they provide an important ecosystem service, nursery habitats have been continually destroyed since 1850 by the construction of dykes and harbour extensions for the purpose of maritime transport (Rochette et al., 2010; Cuvilliez et al., 2009). The resulting growth in the maritime transport sector has contributed to the important development in the regional industrial production. However, this development has particularly harmed the natural habitat of six commercial fish species whose juveniles need nurseries for feeding: bass, sole, flounder, plaice, pout, and whiting (Ifremer, 1999). It has resulted in a decrease in the provisioning ecosystem service of fish resources found in the Seine estuary for final consumption and for intermediate consumption (the fishing sector and other sectors that consume fish as an intermediate input). An increase in the surface and quality of estuarine nursery areas might partly reduce decreases in fish stock, which threaten at least three of the six commercial species mentioned above: plaice, whiting and sole (ICES, 2008). The impact of nursery degradations has been demonstrated and quantified for the population of common sole (Solea solea sp.) by Rochette et al. (2010). Consequently, this species has been selected for our study because of the availability of data and its high commercial value.

Due to the high level of uncertainty and lack of data on the state of most fish stocks in Europe and given the unsustainable harvest of the remaining stocks, measures applied to fish habitats on the basis of the precautionary principle might acquire greater political acceptability in the future. Out of a total of 44 fish stocks in European fishing zones, there is $57 \%$ of the stock whose state is unknown or undefined, only $4 \%$ of the stock is sustainably harvested, and the remaining $32 \%$ (including sole) is overfished, i.e. their capacity to regenerate for the future is endangered (ICES, 2008). In response to these figures, the I-O model developed below is used to answer the following question: what would be the ecological and economic impact of precautionary measures applied to fish habitats while still respecting the principles that environmental damage should be rectified at the source and that the polluter should pay? These three principles are stated in the Marine Strategy Framework Directive (European Parliament and Council, 2008) and the environmental measure considered in this paper is based on them. It consists in restoring half of the high fish density nurseries that have been the most heavily destroyed between 1834 and 2004. The expected impact is a growth in fish stocks, which should increase the resilience of fish populations to fishing activities and their capacity to regenerate for the future.

\section{The ecological-economic I-O model}

The ecological-economic I-O model translates into quantitative terms the qualitative description of the Seine estuary given by the conceptual model mentioned in section 2 . This conversion from qualitative to quantitative description is based on I-O developments that started in 1936 with Leontief until more recently with Victor (1972), Carpentier (1994) and Jin et al. (2003). This Input-Output background is presented below.

\subsection{Input-Output background:}

Input-output analysis was devised initially by Leontief (1936) and progressively improved by Cumberland (1966), Daly (1968), Isard (1968), Leontief (1970) and Victor (1972). A concise description of these models can be found in Miller and Blair (2009), Hannon (2001) and Lixon et al. (2008). Victor (1972) developed an ecological-economic I-O model in the form of a commodity-byindustry table combining economic and environmental commodities. He introduced economic components in monetary terms, while ecological ones were expressed in physical terms. Victor's approach discarded interactions occurring inside the environment, arguing the lack of data on 
ecosystem functioning. In the 1990's, Carpentier (1994) refined the method by increasing the number of ecological goods integrated into the accounting framework. However, contrary to Victor, Carpentier reverted to Isard's idea of modelling interdependencies between ecosystem services, i.e. interactions occurring inside the environment. This could be achieved by closing the ecological-economic cycle. More recently, Jin et al. (2003) have partly closed the sub-cycle for aquatic systems by linking a marine food web to a Leontief I-O table.

The model developed in this paper builds on the methodological developments from the authors mentioned above, with the aim of developing an I-O model that contributes to the two basic principles of Post-Normal Science and ICZM mentioned in section 1: i) allowing high uncertainty issues to be addressed and ii) demonstrating holistic properties. In addressing the second principle first, we have increased the holistic properties of I-O modelling, in that not only provisioning and sink services are considered (e.g. provision of commercial fish from the sea and accumulation of pollutants into rivers) but also the supporting ones (e.g. aquatic habitat provided by estuarine nurseries to fish juveniles). This is achieved by keeping the technical coefficients commonly used in I-O modelling for the estimation of provisioning and sink ecosystem services in scenario simulations. With such coefficients, the consumption of natural resource and pollutant emissions in scenario simulations are calculated in proportion to the total output produced per economic sector. However, for the supporting service considered in this paper (nursery habitats), such simple relations are no longer possible due to too high complexity (e.g. multiple causes producing one effect) and the resulting high uncertainty. Consequently, in scenario simulations, the state of the supporting service of nursery habitats is estimated based on past trends corrected by expert advice to take into account future changes that might occur in the trends. Although bio-physical modelling, statistics and probabilities might offer a more robust alternative than past trends and expert advice, such techniques cannot apply until more data and knowledge have been produced.

The first principle is achieved by relying on past trends and expert knowledge as explained above for the supporting service of estuarine nursery habitats. However, addressing uncertain issues is not enough; uncertainty must also be managed. One part of the uncertainty is dealt with inside the model through sensitivity analysis, which shows the range of values the final results might take (see the error bars on the graphs in Section 6). It is not possible to give results in the form of a single value because of the relative indeterminacy on the model parameters, such as those estimated with past trends and expert knowledge. Another part of the uncertainty has to be treated outside the model, because it covers ecosystem services that could not be quantified. This is due partly to the fact that appropriate data and knowledge were lacking (e.g. detailed population data from the Seine estuary on fish species other than sole) but also to high complexity which generates high levels of indeterminacy (e.g. the impact of each pollutant on the reduced capacity of nursery areas to shelter fish juveniles). In such indeterminate issues, a part of individual judgment and common sense always remains. Consequently, the transparent inclusion of divergent public perspectives and value judgment inside a stakeholder participative process is important in decision-making. The model can be useful to stakeholder participation because it enables the identification and the quantification of trade-offs (as shown in Section 6.3). This makes trade-offs arising from a complex situation more transparent to decisionmakers and other stakeholders, which is an important advantage of stakeholder participative techniques (Munda et al., 1994). Although the model has been designed in order to be coupled eventually with some kind of participative process, this has not been performed.

Addressing the environmental issue of estuarine nursery habitats requires quantifying interdependencies between two ecosystem services (nursery habitats and fish provisioning for human consumption), as well as a partly closing some ecological-economic sub-cycles. In so doing, this paper attempts to improve on the works of Carpentier (1994) and Isard (1968). The approach expanded in this paper is similar to the I-O model developed by Hannon (2001, p. 20), who combines the natural and economic process in a common framework to make possible the formal rejoining of man and nature - of human activity and its environmental repercussions. However, our ecologicaleconomic I-O model differs in the method used to reach that purpose. The method applied by Hannon consists in pricing the value of exchanges between the environment and the economy and adding these 
values to real market economic flows in monetary units. Unlike Hannon's method, ours attributes monetary units only to ecosystem services that can be valued in terms of their direct potential conversion into marketed goods \& services (mostly ecosystem services with direct use, e.g. provisioning services such as fish catch). Physical units are attributed to others (i.e. mostly indirect ecosystem services such as supporting and regulating ones, but also some cultural ones). So, on the one hand, we have introduced ecological and social indicators into the I-O model in physical units (e.g. surfaces of mudflat nurseries), and on the other hand, we have put economic indicators in monetary units (e.g. regional GDP in $\mathrm{M}_{2007}$ ).

The advantage of Hannon's I-O model is that it leads to the calculation of a single GDP indicator adjusted for the environment (the so-called -Gross System Product"). This is useful in the early stages of a decision-making process as a warning signal to show decision-makers how far the economy is off the sustainable path. However at a later stage, when the time has come to select a range of policy measures to move society towards a sustainable path, it might be useful to identify trade-offs to show which stakeholder group will be favoured or disadvantaged (e.g. that could help decision makers to apply compensatory measures prorated to the disadvantage suffered by some stakeholder groups). The trade-offs must be clear and apparent to stakeholders if environmental management is to be operational (Munda et al., 1994; van den Bergh and Nijkamp, 1991). This requires the use of multiple unit models such as the one developed in this paper, which is specifically aimed at identifying and quantifying those trade-offs. An interesting trade-off to quantify might occur, for instance, between the gross operating surplus of companies (Euros) and the fish stocks (tonnes) in the context of restoration programmes for nursery areas $\left(\mathrm{km}^{2}\right)$. If, instead of the three units mentioned, one single aggregated indicator is used to estimate the total net impact of restoration programs, no trade-off can be assessed.

\subsection{Basic equations for our economic system modelling:}

The ecological-economic model developed in this study is an open and static I-O model based on domestic commodity-by-industry tables (Table 1 and Table 2). The tables are composed of two square matrices $(n=m): \mathbf{V}$, the supply matrix, and $\mathbf{U}$, the use matrix (matrices are indicated in bold capital letters, vectors in bold italic lower-case ones and scalar in italic lower-case letters), where both are made of $n$ commodities in lines and $m$ economic sectors in columns; two rectangular matrices $(\mathbf{F}$, a $n \times p$ matrix representing the final demand including leakages from the economy and $\mathbf{Y}$, a $n \times t$ matrix of primary inputs - components of the added value) and four vectors $\left(\boldsymbol{g}^{\boldsymbol{T}}\right.$, a $1 \times m$ line vector of total output per sector $j$, where the small $T$ in exponent means that the vector has been transposed; $\boldsymbol{q}$, a $n \times 1$ column vector of the total demand per commodity $i ; \boldsymbol{m}$, a $1 \times(m+p)$ line vector of interregional and international imports for intermediate and final input consumption; and $\boldsymbol{\mu}, \mathrm{a} 1 \times p$ line vector of total input consumed per category of final demand). All these variables are expressed in monetary terms. The elements of the four matrices are defined as follows. Each $v_{j i}$ represents the value of commodities $i$ produced by each industrial sector $j$ in the region Haute-Normandie $(j=1, \ldots, m ; i=$ $1, \ldots, n)$. Each $u_{i j}$ represents the value of regionally produced commodities $i$ required by each industrial sector $j$ to produce its own output. Each $f_{i k}$ represents the value of regionally produced commodities $i$ consumed by the $p$ categories of final demand $k(k=1, \ldots, p)$ which are the following: final consumption by households, NGO and government, gross fixed capital formation, change in valuables, change in inventories, and international and interregional exports. Leakages such as international and interregional imports have been subtracted from the intermediate and final inputs and put in a separate table in order to have domestic (regional) tables. To ensure identity between the use and the supply table, imports are added as a line vector in the use table, in which each $m_{j}$ represents the imports used by sector $j$ and final demand $k(j=1, \ldots, m+p)$. Each $y_{z, j}$ is the value of primary input $z(z$ $=1, \ldots, \mathrm{t})$ consumed by each industrial sector $j$. There are three categories of primary inputs: compensation of employees (i.e. wages and salaries including social contributions and income tax); net taxes on production; and gross operating surplus (i.e. companies' benefits).

This framework is then augmented by three row vectors of ecological commodities associated with the environmental issue of harbours and nursery areas selected in the previous section. They are expressed 
in physical terms. The four vectors are defined as such: $\boldsymbol{h}^{N}$ (where each $h_{j}^{N}$ represents the amount of nursery areas restored in the ecosystem by sector $j$ ); $\boldsymbol{h}^{S}$, which equals 0 (where each $h_{j}^{S}$ represents the quantity of sole produced in the ecosystem by sector $j$ ); $\boldsymbol{r}^{S}$ (where each $r_{j}^{S}$ represents the quantity of sole consumed by sector $j$ in the region of Haute-Normandie). One scalar $\boldsymbol{r}^{N}$ is used to represent the total amount of nursery areas destroyed by all economic sectors (the amount per sector $j$ is unknown due to high uncertainty, although the total can be estimated). Four scalars give the total values for ecological commodities $-\mathrm{e}^{\mathrm{S}}$ and $e^{N}$ representing the tonnage of sole and the nursery surface area that can be used by the ecosystem, i.e. the stock that remains in the environment after consumption by industrial sectors, natural production by the ecosystem and environmental restoration activities; $e^{\prime S}$ and $e^{N}$, representing the tonnage of sole and the nursery surface area naturally produced by the ecosystem.

The model framework relies on input-output equations that are based on commodity-by-industry tables (Table 1 and Table 2). They are described concisely in Victor (1972) and Lixon et al. (2008).

The equation eq. 1 is the core part of the economic model:

$g^{T}=\left[\left(\mathbf{I}-\mathbf{D}^{\mathrm{T}} \mathbf{B}^{\mathrm{d}}\right)^{-1} \mathbf{D}^{\mathrm{T}}\right] \mathbf{F}^{\mathrm{d}} \mathbf{i}$,

where $\mathbf{I}$ is the $n \times m$ identity matrix (a square matrix so that $n=m$ ); $\mathbf{D}$ is a $n \times m$ matrix of technical coefficients named commodity output proportion calculated from intermediate outputs in the supply table; $\mathbf{B}$ is a $n \times m$ matrix of input technical coefficients calculated from intermediate inputs in the use table; $\mathbf{i}$ is a unity column vector $1 \times n$ (not to be mistaken for $i$ that symbolises commodities). Other symbols are already described above. $\mathbf{D}^{\mathbf{T}}$ is the matrix of the commodity output proportions $d_{i j}$, which are technical coefficients defined under the industry-based technology assumption. $\mathbf{B}$ is the matrix of the input technical coefficients $b_{i j}$. Both technical coefficients $\mathbf{D}$ and $\mathbf{B}$ are calculated respectively on the basis of matrices $\mathbf{V}$ and $\mathbf{U}$, as in Lixon et al. (2008). Exponent $d$ shows that consumption concerns inputs used in the Haute-Normandie region, which have been domestically produced in the region. The final demand $\mathbf{F}$ is one of the variables together with technical coefficients $\mathbf{B}$, used to simulate a change caused by the development of an economic activity and ecosystem services inside a scenario simulation.

International imports for intermediate consumption $\left(\boldsymbol{m}_{\text {intern }}\right)$ and for final consumption $\left(\boldsymbol{f m}_{\text {intern }}\right)$ are given by exogenous forecasts from OECD (2009) and FPB (2008). Interregional imports are calculated prorated to the total output per sector, $\widehat{\boldsymbol{g}}$, and to the total input per category of final demand, $\widehat{\boldsymbol{\mu}}$ (the circumflex means that the line vector has been transformed into a diagonal matrix). The row vector of total imports per sector $(\boldsymbol{m})$ is calculated as follows:

$m=m_{\text {intern }}+\mathrm{i}^{\mathrm{T}} \mathrm{A}_{\mathrm{reg}}^{\mathrm{m}} \widehat{g}+f m_{\text {intern }}+\mathrm{i}^{\mathrm{T}} \mathrm{A}_{\mathrm{reg}}^{\mathrm{fm}} \widehat{\mu}$

Where $\mathbf{A}_{\text {reg }}^{\mathbf{m}}$ and $\mathbf{A}_{\text {reg }}^{\mathbf{f m}}$ are the matrices of technical coefficients of interregional imports used by economic sectors as intermediate inputs and those used by the final demand as final inputs.

The economic impacts on primary inputs $(\mathbf{Y})$ are calculated as follows:

$y_{1 j}^{t_{n}}=\frac{y_{1, j}^{t_{0}}}{g_{j}^{t_{0}}} g_{j}^{t_{n}}-\frac{\left(y_{2, j}^{t_{n}}\right)_{\text {Virtual }}}{2} \quad(z=1=$ compensation of employees $)$

$y_{2 j}^{t_{n}}=\frac{y_{z, j}^{t_{0}}}{g_{j}^{t_{0}}} g_{j}^{t_{n}} \quad(z=2=$ net taxes on production $)$ 
$y_{3 j}^{t_{n}}=g_{j}^{t_{n}}-\sum_{i=1}^{n} b_{i j}^{t_{n}} g_{j}^{t_{n}}-m_{j}^{t_{n}}-y_{1 j}^{t_{n}}-y_{2, j}^{t_{n}}-\left(y_{2, j}^{t_{n}}\right)_{\text {Virtual }} \quad$ (z=3= gross operating surplus $)$

In eq. 3, half of the restoration costs, represented by the virtual tax $\left(y_{2, j}^{t_{n}}\right)_{\text {Virtual }}$, are subtracted from the compensation of employees, assuming that the other half will consist in a decrease in the gross operating surplus, i.e. companies' benefits. This is because in the Seine estuary, restoration costs are directly borne by sectors responsible for nursery destruction (Polluter Pays Principle). With eq. 5, the gross operating surplus is estimated at an industry level as a residual variable after subtracting the consumption of intermediate inputs, imports, compensation of employees, net taxes on production and the virtual tax from the total output per sector. Hence, we assume that the increase of production costs, caused by the restoration of nursery areas, leads to a decrease in the gross operating surplus and compensation of employees, rather than to a price increase. The main assumption here is that each sector $j$ cannot increase its prices. They are fixed at the national or international level and the increase of production costs in the Haute-Normandie region does not affect prices.

The variation in the gross operating surplus has an impact on the final consumption of households that benefit from dividend incomes. The same occurs with the variation in compensation of employees. To take that aspect into account, we have multiplied the 2007-2015 growth factor by the household final demand of 2007 in the matrix $\mathbf{F}^{\mathbf{t}_{\mathbf{0}}}$. The growth factor is exogenous to the model and comes from forecasts from OECD (2009) and FPB (2008) for household final consumption. Then, we have modified the result prorated to the 2007-2015 variation of the income available for final consumption caused by nursery restoration programmes, assuming that households purchase commodities in direct proportion to their income. To calculate the income available for final consumption, we have subtracted taxes on incomes, savings and social contributions from compensation of employees and added the share of the gross operating surplus which is paid to shareholders in the form of dividends.

\subsection{Equations for modelling the economic system in policy option scenarios:}

Since the supply-use tables in our ecological-economic I-O model correspond to the economy of the region of Haute-Normandie in 2007, they have been updated for $2015\left(t_{n}\right)$, which is the horizon year modelled in this paper. This was done using exogenous forecasts for 2015 for final demand values given by OECD (2009) and FPB (2008) and replacing the 2007 values by 2015 values in the matrix $\mathbf{F}^{\mathbf{t}_{\mathbf{n}}}$ in eq. 1 . The use of final demand forecasts as a lever to simulate a change in the economic system in 2015 follows the example of Carpentier (1994) and Lixon et al. (2008).

The forecasts from OECD (2009) and FPB (2008) have been used for all commodities except for fishing products. The final demand for fishing products $(i=3)$ is endogenised in the model and depends on the restoration of nursery areas decided by stakeholders in the process of scenario building. Three assumptions underpin the endogenisation. First, fish production is assumed to be demand-driven; second, the increase in the stock of sole in the Eastern channel leads to an increase in the allocation of EU fishing quotas; third, the rise in fish captures in the Eastern channel substitutes international importations. Stemming from these assumptions, the impact of the stock increase can be simulated by raising the regional fish demand in proportion to the rise in captures, whose estimation is based on the rise in fish stock in the Eastern channel due to nursery restoration. This is calculated as follows:

$$
f_{3, k}^{t_{n}}=f_{3, k}^{t_{0}}\left(1+\frac{x_{t_{0}}^{S}}{x_{t_{0}}^{T o t}} \sum_{j=1}^{m} \frac{r_{j, t_{n}}^{S}-r_{j, t_{0}}^{S}}{r_{t j, 0}^{S}}\right)
$$

In eq. 6 , the final demand $f_{3, k}^{t_{n}}$ is prorated to the rate of variation of the total sole catch between the reference year $t_{0}\left(r_{j, t_{0}}^{S}\right)$ and the horizon year $t_{n}\left(r_{j, t_{n}}^{S}\right)$, and to the share of sole sold $\left(x_{t_{0}}^{S}\right)$ in the total sales of fish products $\left(x_{t_{0}}^{T o t}\right)$ in the Seine estuary, in monetary value, as given in Ifremer (2003). The 
value of $\sum_{j=1}^{m+p} r_{j, t_{0}}^{S}$ is an observed value in the reference year taken from ICES (2007) and OFIMER (2003), while the value of $\sum_{j=1}^{m+p} r_{j, t_{n}}^{S}$ is a function of the area of nursery restored (calculation explained below).

Unlike Carpentier (1994) and Lixon et al. (2008), we used a second lever to simulate changes in economic sectors and ecosystem services. In addition to final demand values, we also modify the consumption of intermediate inputs of fish products $\left(u_{2, j}\right)$ to take into account the fact that the rise in marine fish stock might result in increased captures which would not only fulfil final demand, but also intermediate demand from food production industries and hotels \& restaurants. It is assumed that these sectors will use additional regional fish products as an intermediate input to produce their own output instead of international imports. The calculation is the same as in eq. 6 , except that the symbol $f_{3, k}$ is replaced by $u_{3, j}$. Modifying intermediate input values implies that input technical coefficients in matrix $\mathbf{B}$ are modified and will change the results from eq. 1. This is an original point in this paper.

Nursery restoration programmes do not only affect the stock of sole. The costs incurred by sectors undertaking restoration activities also have an impact on the economic system. This impact is calculated as follows:

$f_{22,4}^{t_{n}}=f_{22,4}^{t_{0}}+\Psi s$

Where $\Psi$ is the unit cost incurred to restore 1 ha of nursery and equals $M €_{2007} 0.277$ per ha (Port Autonome du Havre, 2000) ${ }^{2}$. This activity is carried out by companies providing construction services and results in investments in fixed capital in the form of special dyke construction products $(i=22)$ built for the restoration of nursery areas $(s) . s$ is fixed by stakeholders inside the participative process for the purpose of scenario building. This increases the gross fixed capital formation $(k=4)$ in construction products $\left(f_{22,4}\right)$.

The restoration costs, $\Psi$, are paid according to a cost allocation rule decided by stakeholders inside a participative process. This rule allocates a share $\left(\theta_{j}\right)$ of the total restoration cost to each sector $j . \theta_{j}$ should be set by stakeholders in a participative process, however, for the purpose of the numerical application presented in this paper, we have arbitrarily set $\theta_{j}$ according to a cost allocation rule explained in Section 5. The effect of the cost allocation rule is an increase in production costs, which results in a decrease in the gross operating surplus of each sector $j$ as well as in the compensation of employees as shown in eq. 3 and eq. 5. This decrease is estimated by calculating the amount of restoration costs incurred by each sector $j$. The result is a virtual tax inserted as an additional row in the primary inputs of the Use Table. The virtual taxes are calculated as follows:

$$
\left(y_{2, j}^{t_{n}}\right)_{\text {Virtual }}=\Psi S \theta_{j}
$$

\subsection{Modelling of the ecological-economic system:}

Victor (1972) developed basic equations for ecological commodities which are still in use today, inter alia Jin et al. (2003) and Lixon et al. (2008). Victor's basic equations for ecological commodities are well-suited to ecological inputs which are used directly, e.g. provisioning services (e.g. wood resources provided by forests) or sink services (e.g. emissions of pollutants into the environment). Nevertheless, for the consideration of supporting services, they must be modified, because their use is indirect and depends on multiple non-linear causes. Such modifications are a step towards the improvement suggested by Carpentier (1994) mentioned in section 3.1.

\footnotetext{
${ }^{2} \mathrm{M}_{2007}=$ Million Euros to be spent in 2015 but expressed in prices of the year 2007.
} 
The supporting service of fish nurseries is destroyed each year $\left(\boldsymbol{r}^{N}\right)$ by economic activities. However, it is impossible to distinguish the responsibility of each economic sector in nursery destruction. This depends on multiple factors : hydro-sedimentary dynamics, harbour expansion, the construction of dykes for water transport, the construction of the Normandy Bridge in the 1990's, the time lag between both constructions and their effect on hydro-sedimentary dynamics, etc (Cuvilliez et al., 2009). This indeterminacy problem is partly dealt with by using an average value for $\boldsymbol{r}^{N}$ based on past trends, making the assumption that they will continue for the next 11 years. In order to take into account recent sedimentary evolutions, the very unlikely trends have been eliminated, based on advice from experts in the Seine hydro-sedimentary dynamics.

The impact of nursery annual losses $\left(\boldsymbol{r}^{N}\right)$ on the total nursery natural stock $\left(e^{N}\right)$ is calculated by eq. 9 in which $\boldsymbol{r}^{N}$ includes natural and human-induced evolutions of nursery areas.

$e_{t_{n}}^{N}=e_{t_{0}}^{N}+\left(\sum_{j=1}^{m} h_{j}^{N}-\boldsymbol{r}^{N}\right) \times\left(t_{n}-t_{0}\right)$

where $h_{j}^{N}$, the surface of nursery annually restored by sector $j$, is determined by the surface area of nursery to be restored $(s)$. This is fixed by stakeholders for the purpose of scenario building inside a participative process. The allocation of $s$ across sectors is prorated to $\theta_{j}$ and is set by stakeholders for cost allocation as in eq. 8 .

\subsection{Modelling of the ecological system:}

In the environmental issue selected in this paper, the interactions occurring inside the ecological systems between two environmental assets concern nursery areas $\left(e^{N}\right)$ and the stock of sole species $\left(e_{\text {Eastern }}^{S}\right) . e_{\text {Eastern }}^{S}$ is calculated in tonnes by the following equations (based on data from ICES, 2007 ; and Rochette et al., 2010):

$\left(e_{t_{n}}^{S}\right)^{\text {Eastern }}=\left(e_{t_{0}}^{S}\right)^{\text {Eastern }}(1+a)$,

eq. 10

$a=0.142\left[\frac{A_{t_{n}}-A_{t_{0}}}{A_{t_{0}}}\right]$,

where $\left(e_{t_{0}}^{S}\right)^{\text {Eastern }}$ is given by ICES (2007); $t_{0}$ is the reference year 2007; $a$ is the variation rate of sole juveniles in the Eastern channel due to the modification in nursery surface areas; 0.142 is the contribution of sole juveniles (age 0 , i.e. $<1$ year) in the Seine estuary to the whole of the Eastern channel stock in 2004; $A_{t_{0}}$ and $A_{t_{n}}$ are the abundance of sole juveniles $<1$ year (in number of individual fish) in the Seine estuary in the year 2004 (the reference year) and 2015 (the horizon year) respectively (Table 3 ). Both $A_{t_{0}}$ and $A_{t_{n}}$ are calculated by multiplying the juvenile density index at age 0 from Table 3 by the nursery surface area at the reference year $t_{0}\left(e_{t_{0}}^{N}\right.$ from Table 3$)$ and the horizon year 2015 ( $e_{t_{n}}^{N}$ from eq. 9).

Finally, the sole stock $\left(e_{t_{n}}^{S}\right)^{\text {Eastern }}$ is down-scaled from the area of the Eastern channel to the Seine estuary to estimate $\left(e_{t_{n}}^{S}\right)^{\text {Seine }}$. This is calculated by the following equation:

$\left(e_{t_{n}}^{S}\right)^{\text {Seine }}=\left(e_{t_{n}}^{S}\right)^{\text {Eastern }}-0.858\left(e_{t_{0}}^{S}\right)^{\text {Eastern }}$,

where 0.858 is the fraction of the total stock of sole in the Eastern channel which is not supplied by the Seine estuary - a calculation based on data from Rochette et al. (2010) and ICES (2007).

The impact of the stock of sole on captures by the fishing sector for the horizon time $t_{n}$ is calculated by multiplying eq. 10 with the capture rate in Haute-Normandie $\left(\boldsymbol{C}_{\boldsymbol{i}}\right)$ given by ICES (2007). This gives 
the total catch of sole consumed by the $j$ economic sectors and the $p$ categories of final demand $\left(\sum_{j=1}^{m+p} r_{j, t_{n}}^{S}\right)$.

Table 1. Green supply table used in the ecological-economic I-O model.

\begin{tabular}{|c|c|c|c|c|}
\hline & & $\begin{array}{l}\text { Economic sectors } \\
(\mathrm{j}=1, \ldots, \mathrm{m})\end{array}$ & Ecosystem & Total \\
\hline $\begin{array}{l}\text { Economic cor } \\
(\mathrm{i}=1, \ldots, \mathrm{n})\end{array}$ & S $(M €)$ & $\begin{array}{c}\mathbf{V} \\
v_{i j}\end{array}$ & & $q_{i}$ \\
\hline Total $(\mathrm{M} €)$ & & $g_{j}$ & & $\sum_{i=1}^{n} q_{i}$ \\
\hline Ecological & Nursery $\left(\mathrm{km}^{2}\right)$ & $h_{j}^{N}$ & $\left(e^{\prime N}\right)^{\text {Seine }}$ & $\sum_{j=1}^{m} h_{j}^{N}+\left(e^{\prime N}\right)^{\text {Seine }}$ \\
\hline commodities & Sole $(\mathrm{t})$ & $h_{j}^{S}=0$ & $\left(e^{\prime S}\right)^{\text {Seine }}$ & $\sum_{j=1}^{m} h_{j}^{S}+\left(e^{\prime S}\right)^{\text {Seine }}$ \\
\hline
\end{tabular}

Table 2. Green use table used in the ecological-economic I-O model.

\begin{tabular}{|c|c|c|c|c|c|}
\hline & & $\begin{array}{l}\text { Economic sectors } \\
(\mathrm{j}=1, \ldots, \mathrm{m})\end{array}$ & $\begin{array}{l}\text { Final demand } \\
(\mathrm{k}=1, \ldots, \mathrm{p})\end{array}$ & Ecosystem & Total \\
\hline $\begin{array}{l}\text { Economic con } \\
(\mathrm{i}=1, \ldots, \mathrm{n})\end{array}$ & odities (M€) & $\begin{array}{c}\mathbf{U} \\
u_{i j}\end{array}$ & $\begin{array}{c}\mathbf{F} \\
f_{i k}\end{array}$ & & $q_{i}$ \\
\hline Imports (M€) & & & & & $\sum_{j=1}^{m+p} m_{j}$ \\
\hline $\begin{array}{l}\text { Primary inputs } \\
(\mathrm{z}=1, \ldots, \mathrm{t})\end{array}$ & & $\begin{array}{c}\mathbf{Y} \\
y_{z j}\end{array}$ & & & $\sum_{j=1}^{m} y_{z j}$ \\
\hline Total $(\mathrm{M} €)$ & & $g_{j}$ & $\mu_{k}$ & & $\sum_{j=1}^{m}\left(g_{j}\right)+\sum_{k=1}^{p}\left(\mu_{k}\right)$ \\
\hline & Nursery $\left(\mathrm{km}^{2}\right)$ & $r^{N}$ & & $\left(e^{N}\right)^{\text {Seine }}$ & $r^{N}+\left(e^{N}\right)^{\text {Seine }}$ \\
\hline commodities & Sole (t) & $r_{j}^{s}$ & & $\left(e^{s}\right)^{\text {Seine }}$ & $\sum_{j=1}^{m} r_{j}^{S}+\left(e^{S}\right)^{\text {seine }}$ \\
\hline
\end{tabular}

\section{Data}

Economic data were acquired from the national Supply-Use I-O tables published by Eurostat (2009). First of all, the national matrices were updated from 2005 to 2007. Secondly, they were regionalised to the scale of the French region of Haute-Normandie, based on techniques developed inter alia in McDonald (2005) and discussed in Riddington et al. (2006). The conventional methods were completed with data from the MEDDAT (2009) on interregional flows of goods between the French regions. The SLQ technique was applied for the interregional flows of services (Miller and Blair, 2009).

Data on juveniles of Solea solea sp. (common sole) per $\mathrm{km}^{2}$ (Table 3) and data on the evolution of nursery areas in the Seine estuary from 1834 to 2004 were calculated from historical maps (Rochette et al., 2010). The impact of variation in nursery areas on the stock of sole and on captures by the fishing sector is based partly on these data and partly on data from ICES (2007) on the sole stock in the Eastern channel. Some data do exist for other ecosystem services related to nursery areas. 
Table 3. Abundance of sole juveniles at age 0 ( $<1$ year) located in nursery areas in the Seine estuary in 2004 (aggregated into 2 bathymetry categories). Source: the values of the table are the estimations of the habitat suitability model developed by Rochette et al. (2010).

\begin{tabular}{|c|c|c|c|c|}
\hline $\begin{array}{l}\text { Bathymetry } \\
\text { (m) }\end{array}$ & Sediments & $\begin{array}{c}\text { Nursery } \\
\text { surface area }\left(\mathbf{k m}^{2}\right)\end{array}$ & $\begin{array}{l}\text { Juvenile density index at age } 0 \\
\text { (individuals } / \mathbf{k m}^{2} \text { ) }\end{array}$ & $\begin{array}{c}A_{t_{0}} \\
\text { Juvenile abundance index } \\
\text { (individuals) }\end{array}$ \\
\hline $\mathbf{a}$ & b & $\mathbf{C}$ & d & column $\boldsymbol{c} \times \boldsymbol{d}$ \\
\hline$<-3[; 8[$ & Gravels & 6.40 & 31.06 & 198.78 \\
\hline$[8 ; 20]$ & Gravels & 2.70 & 4.42 & 11.95 \\
\hline$<-3[; 8[$ & Sand & 108.24 & 50.62 & 5478.44 \\
\hline$[8 ; 20]$ & Sand & 34.33 & 7.31 & 251.02 \\
\hline$<-3[; 8[$ & Silt & 41.66 & 68.82 & 2866.89 \\
\hline$[8 ; 20]$ & Silt & 3.06 & 11.41 & 34.96 \\
\hline Total & & 196.38 & $\begin{array}{c}45.02 \\
\text { (mean) }\end{array}$ & 8842.03 \\
\hline
\end{tabular}

\section{Policy scenario}

Between 1834 and 2004, dyke construction and harbour expansion modified the internal part of the Seine estuary. The modifications transformed $33 \%$ of the estuary's potential nursery area into land area (Rochette et al., 2010). The prevailing nursery losses are in the sand sediment areas. The area of shallow sandy nurseries ${ }^{3}$ decreased by $147.5 \mathrm{~km}^{2}$. From that observation we built three scenarios that we have simulated in the model: a business as usual" scenario (BAU); a scenario of nursery restoration with costs borne by harbours; and another one with cost sharing. In all scenarios, the stock of sole in the Seine estuary and the economic results of the fishing sector depend on the variations in nursery areas $\left(\boldsymbol{r}^{N}\right)$.

\subsection{BAU scenario:}

In the BAU scenario, no restoration is undertaken in nursery areas. The natural and human-induced losses in nursery areas $\left(\boldsymbol{r}^{N}\right)$ are estimated for 2015, based on the extrapolation of habitat destruction estimated by Rochette et al. (2010). From these data, an average of three past trends in hydrosedimentary dynamics in the nurseries of the Seine estuary was calculated: the trend from 1978-2004, from 1834-2004 and a status quo trend in which we consider that the 2004 situation had reached a hydro-sedimentary equilibrium. After the elimination of unlikely trends based on advice from experts in hydro-sedimentary dynamics, the resulting average annual variation rate of nursery areas with high juvenile density $\left(\geq 45 \text { individuals } / \mathrm{km}^{2}\right)^{4}$ amounts to $+0.59 \mathrm{~km}^{2}$ in the BAU scenario. This slight increase in nursery areas is due both to the natural evolution of the Seine estuary and also to a strong human influence in hydro-morphological and sedimentary dynamics. This increase mainly concerns sand nurseries, but hides a decrease in silt nurseries (the most productive ones in terms of sole juveniles).

Regarding economic trends, the future values for 2015 have been simulated using exogenous forecasts for the elements of matrix F from OECD (2009) and FPB (2008) given in Table 4. These forecasts have been used for all commodities including fishing and construction products. For instance, for household final consumption, the multiplication factor from the last column $(1,076)$ has been applied to each of the cells of the use table corresponding to household final consumption (F matrix) in HauteNormandie in 2007. That is to say, no distinction has been made between the 35 commodities consumed by households. They are all assumed to vary in the same rate between 2007 and 2015 . In addition, the variation rate is supposed to be the same for France and for Haute-Normandie. Both

\footnotetext{
${ }^{3}$ We consider only shallow areas $(<8 \mathrm{~m})$ because sandy nursery areas deeper than $8 \mathrm{~m}$ show a very low density of sole juveniles ( 7 to 8 individuals $/ \mathrm{km}^{2}$ ). However, in the number of $147.5 \mathrm{~km}^{2}$ we exclude depths between [3m and $5 \mathrm{~m}$ [ because their surface has actually increased between 1834 and 2004 .

${ }^{4}$ This value corresponds to the average density in the Seine estuary (Table 3 ).
} 
simplifying assumptions are necessary given the lack of forecast data detailed at commodity levels and regional scales.

Table 4. Annual growth rate forecasts for final demand components and imports in France over the 20082015 period.

\begin{tabular}{|c|c|c|c|c|c|c|c|c|c|}
\hline \multirow[b]{2}{*}{ Years } & \multicolumn{8}{|c|}{ Percentage of variation compared to past year (\%) } & \multirow{2}{*}{$\begin{array}{c}\text { Total variation on 2008-2015 } \\
\text { (Factor to multiply to } 2007 \\
\text { values) }\end{array}$} \\
\hline & 2008 & 2009 & 2010 & 2011 & 2012 & 2013 & 2014 & 2015 & \\
\hline Household final consumption & 1.0 & 0.6 & 0.3 & 1.5 & 1.2 & 1.0 & 0.9 & 0.8 & 1.076 \\
\hline Government final consumption & 1.1 & 1.5 & 1.3 & 0.8 & 0.8 & 0.7 & 0.7 & 0.6 & 1.077 \\
\hline Gross Fix Capital Formation & 0.4 & -6.8 & -0.3 & 3.1 & 2.1 & 2.0 & 1.9 & 1.9 & 1.039 \\
\hline Exportations of goods and services* & -0.6 & -11.0 & 4.7 & 6.4 & 7.5 & 7.8 & 7.8 & 7.5 & 1.323 \\
\hline Importations of goods and services* & 0.6 & -10.0 & 2.9 & 6.3 & 4.8 & 3.8 & 3.4 & 3.1 & 1.148 \\
\hline
\end{tabular}

Sources: predictions from OECD (2009) for France on the period 2008-2011 and from FPB (2008) for the Euro zone - 12 member states - on the period 2012-2015).

* The percentage of variation relates to international imports and exports, not interregional ones.

** The multiplication factors in last column are calculated as follows: $\left(1+a_{2008}\right) \times\left(1+a_{2009}\right) \times\left(1+a_{2010}\right) \times \ldots \times\left(1+a_{2015}\right)$, where $a_{i}$ is the percentage of variation in the year $i$ compared to past year (in decimal value).

\subsection{Restoration scenario with costs borne by harbours:}

With the aim of illustrating the potential of the ecological-economic model developed in this paper, we suggest an ambitious scenario where half of the shallow $(<8 \mathrm{~m}$ depth) sandy nursery losses would be restored over the period 2004-2015, i.e. 670.36 ha per year for an annual cost of $\mathrm{M}_{2007}$ 185.94. The resulting average annual rate of variation in high density nursery areas amounts to $+5.23 \mathrm{~km}^{2}$. This last figure includes increases in nursery areas through restoration as well as natural and human-induced variation in non-restored areas. In this scenario, the restoration cost is taken charge of entirely by the harbour sector $(j=28)$. This cost allocation rule is integrated into the model by setting $\theta_{28}$ to unity and all other $\theta_{j}$ to zero in eq. 8 .

Regarding economic trends, the future values for 2015 have been simulated using the same forecasts as in the BAU scenario except for fishing and construction products. Their value is endogenised by the model and calculated as in eq. 6 and eq. 7. The value of intermediate inputs, $\mathbf{U}$, for fish products is also endogenised. Regarding construction products, the endogenisation concerns only the gross fixed capital formation. The seven other components of the final demand $\mathbf{F}$ are given by the external forecasts mentioned above in Table 4 (except the interregional exports per commodity, which are estimated prorated to the 2007-2015 variation of the sum of the total intermediate demand; the final demand by households, NGO and government; and the gross fixed capital formation).

\subsection{Restoration scenario with cost sharing:}

This restoration scenario is identical to the previous one except that restoration costs are shared between harbours and all other sectors directly concerned by maritime transport. In order to illustrate the potential of the model, we arbitrarily set a share of the restoration cost per company prorated to the annual amount of commodities (in tonnes) transported on water by each sector. Maritime transport is indirectly responsible for the destruction of fish nursery areas (caused by the fairway ${ }^{5}$ and dykes required). Harbours do not transport commodities, but can take on responsibility for the companies which do transport them in Haute-Normandie, yet are located outside the region. Harbours can modify the charges of their services provided to those companies, although this has not been considered in our model. The allocation of restoration costs is taken into consideration inside $\theta_{j}$ in eq. 8 .

\footnotetext{
${ }^{5}$ Fairway: navigable channel built in the Seine river mouth.
} 


\section{Results and discussion}

The results from both restoration scenarios are compared with the BAU scenario at the horizon time, 2015. All values are expressed in base 100, i.e. the values from the BAU scenario set to 100 . When only one restoration scenario is shown, this is because results are equal in both restoration scenarios. On all graphs, the vertical black bars on the histograms have been calculated from a sensitivity analysis we carried out. For that purpose, we made the model parameter values vary at random 500 times inside minimum and maximum margins selected from observed data ${ }^{6}$. This allows us to take into account the relative uncertainty concerning the value adopted by the model parameters at the horizon time of 2015. This technique addresses the kind of uncertainty named - spred" by Funtowicz and Ravetz (1994) which relates to degree of precision, what experimentalists call -randm error" (in our case, caused by inherent complex and chaotic ecosystem dynamics).

We also addressed a second kind of uncertainty underlined by the two authors. It relates to the degree of accuracy or what experimentalists call -systematic error" ", which in our case, is caused by the architecture of the model (static technical coefficients and linear relationships mainly). We calculated the systematic error from the ex post analysis of past projections (Lutz and Sanderson, 2001). This consisted in running the model using final demand values ${ }^{7}$ for past years (from 1999 to 2006) and comparing the results given by the model with observed values. The minimum and maximum values have been selected and aggregated to those obtained with the 500 random values. The result has been used as margins for the range showed by the error bars on the graphs in section 6 .

\subsection{Environmental impacts of nursery restoration scenarios:}

Figure 1 shows that both restoration scenarios contributed towards estuarine nursery areas with high juvenile sole density in 2015 by $43.1 \%$, compared to a situation with no restoration. Although this percentage is the most probable one on the basis of available data and knowledge, it is highly uncertain due to complexity and a lack of data. However, the sensitivity analysis shows that restoration scenarios might result in a lower increase $(+42.6 \%)$ or even in a much greater one $(+66.5 \%)$ depending on indeterminate natural and human-induced evolution of non-restored areas. After inserting the value for nursery areas in 2015 into eq. 10 and eq. 11, the amount of sole biomass provided by the Haute-Normandie to the Eastern channel stock exceeds the BAU scenario by $44.2 \%$ (within the range of uncertainty: $35.9-69.9 \%$ ).

\footnotetext{
${ }^{6}$ Idealistically, a frequency distribution should have been calculated in order to observe the form of the distribution and then decide whether the maximum and the minimum make sense. However, this could not be done because the observed data on which they are based are very scarce. For instance, for one of the parameters that we made vary at random 500 times, the annual rate of growth of the surface of nursery areas, there is only five observed values on which we can calculate a maximum and a minimum annual growth rate $(1834,1910$, $1978,1995,2004)$. This is not enough data to establish a distribution curve of frequencies.

${ }^{7}$ Household, NGO and government final consumption, exportations, change in valuables and in inventories, gross fix capital formation
} 


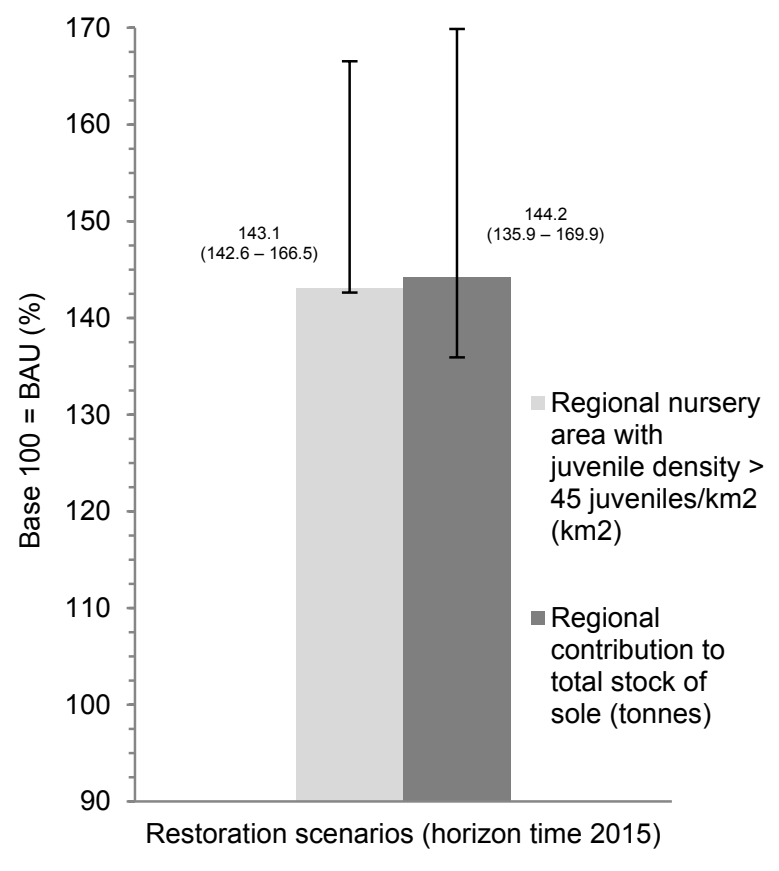

Figure 1. Environmental impacts of nursery restoration scenarios (2007-2015).

\subsection{Macro-economic impacts of nursery restoration scenarios:}

Regarding the three macro-economic indicators mentioned below, both restoration scenarios do not differ greatly from the BAU scenario as shown in Figure $2:+0.2 \%$ for the total industrial output, and $-0.2 \%$ for the GDP as well as for the total gross operating surplus (i.e. benefits made by economic sectors). There is also a loss of $-0.2 \%$ in the total compensation of employees (not shown on the graph). This means that without reductions in individual wages and salaries, the number of jobs in 2015 will be $0.2 \%$ lower in both restoration scenarios than in a situation without restoration (BAU). These slightly negative macro-economic impacts are due to the assumption that to reduce the benefit losses caused by nursery restoration, companies would lower wages and salaries (compensation of employees) by half the restoration costs - the other half being paid by a reduction in benefits. This results in a decrease of household consumption, which in turn slows down production, reduces GDP and in the end, the total gross operating surplus.

However, our results should rather be considered as lower bounds than as complete impact values, because all the costs have been taken into account but not all the ecosystem services generated by nursery restoration. Nevertheless, it would be possible to use the model developed to assess some other ecosystem services provided by nurseries, if appropriate data and knowledge were generated by natural scientists. This concerns i) the provisioning service of six commercial fish other than Solea solea (common sole): Dicentrarchus labrax, Platichthys flesus, Pleuronectes platessa, Trisopterus luscus, Trisopterus minutus, and Merlangius merlangus ${ }^{8}$; ii) the life support service provided to these six species; iii) the regulating service of flood control; iv) the cultural services of recreational fishing and v) the regulating services of natural contaminant buffering. As long as data and knowledge are not available, results on interdependencies between these five ecosystem services and the economic system remain largely uncertain. Bio-physical modelling or comparisons between the Seine estuary and an unpolluted reference site as carried out in Rochette et al. (2010) are approaches that might reduce the uncertainty. However, as long as new data and knowledge are not available, this is typically the kind of issue for which a final decision relies more on individual judgement and common sense than on scientific evidence. As explained in Sections 1 and 3.1, stakeholder participation is an

\footnotetext{
${ }^{8}$ Bass, flounder, plaice, pouting, poor cod, and whiting.
} 
interesting approach to integrate individual judgment and common sense to decision-making in a transparent manner.

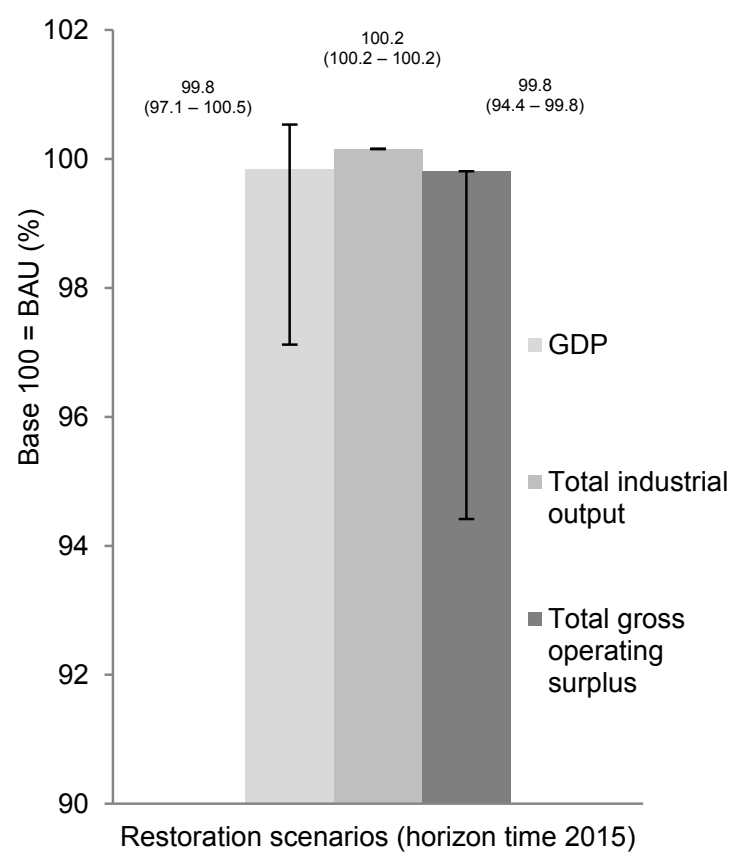

Figure 2. Macro-economic impacts of nursery restoration scenarios (2007-2015).

6.3. Trade-offs between sectors in nursery restoration scenarios:

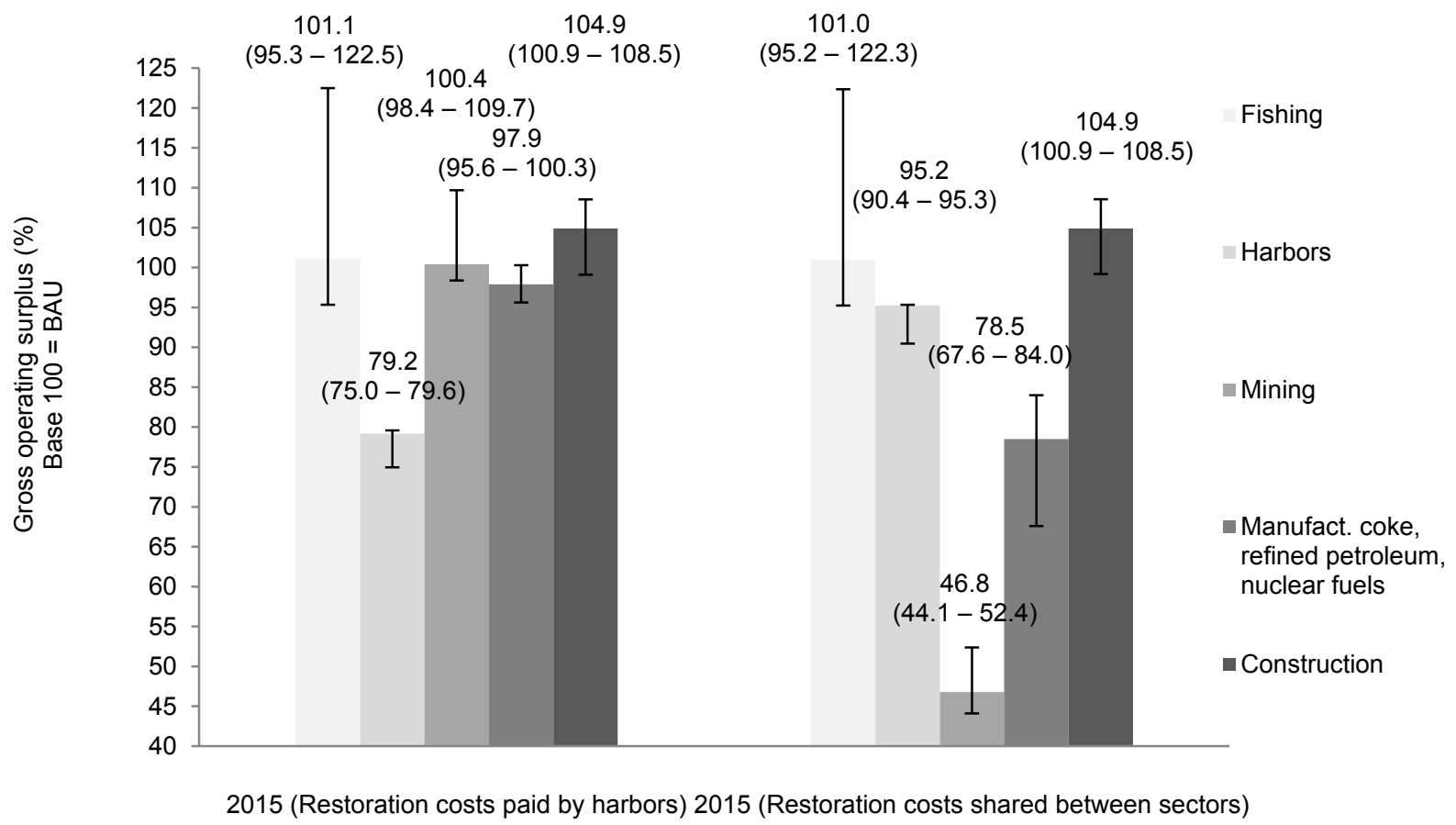

Figure 3Figure 3 shows that in both nursery restoration scenarios, the gross operating surplus of the fishing sector is higher than in the BAU scenario: $+1.1 \%$ and $+1.0 \%$ respectively. This positive impact is due to an increase in the stock of sole in the Eastern channel caused by the restoration of nursery areas in Haute-Normandie. The consequence is an increase in the sales of fish landed in the region's harbours, which substitute international imports. The construction sector runs along the same lines: 
$+4.9 \%$ in both restoration scenarios. This rise is generated by the increased demand for special dyke constructions for nursery restoration. The growth in both, fishing and construction sectors, generates positive impacts on all other sectors that supply them with intermediate inputs (not shown on the graph). However, there are also negative impacts. Nursery restoration generates high production costs for three sectors: harbours, mines and the coke manufacturing, refined petroleum products $\&$ nuclear fuels sector. These high costs reduce their gross operating surplus. A trade-off has therefore occurred between the maximization target of industrial gross operating surplus and nursery restoration targets.

In the restoration scenario with costs borne by harbours, the gross operating surplus of the harbour sector reaches $79.2 \%$ of the level that would be achieved in the BAU, whereby harbours from HauteNormandie might be outcompeted by other harbours from border regions and countries as well as by train and road transport sectors. This problem is partly solved by the restoration scenario with cost sharing. In this scenario, the gross operating surplus of harbours reaches, in $2015,95.2 \%$ of the level that would be achieved in the BAU - a much higher level than in the first restoration scenario - and shows that financial losses have been considerably reduced for the harbour sector. However, this sector remains one of the most impacted in the restoration scenario with cost sharing along with the mining sector ( $46.8 \%$ of the BAU value) and the coke manufacturing, refined petroleum products \& nuclear fuels sector $(78.5 \%$ of the BAU value). This is a result of the allocation rule of restoration costs (explained in Section 5.3) which makes the harbour sector pay one of the highest shares: $23 \%$ of the total annual cost. This is similar to the mining sector, whose share equals $40 \%$, and the coke manufacturing, refined petroleum products \& nuclear fuels sector, whose share comes to $19 \%$.

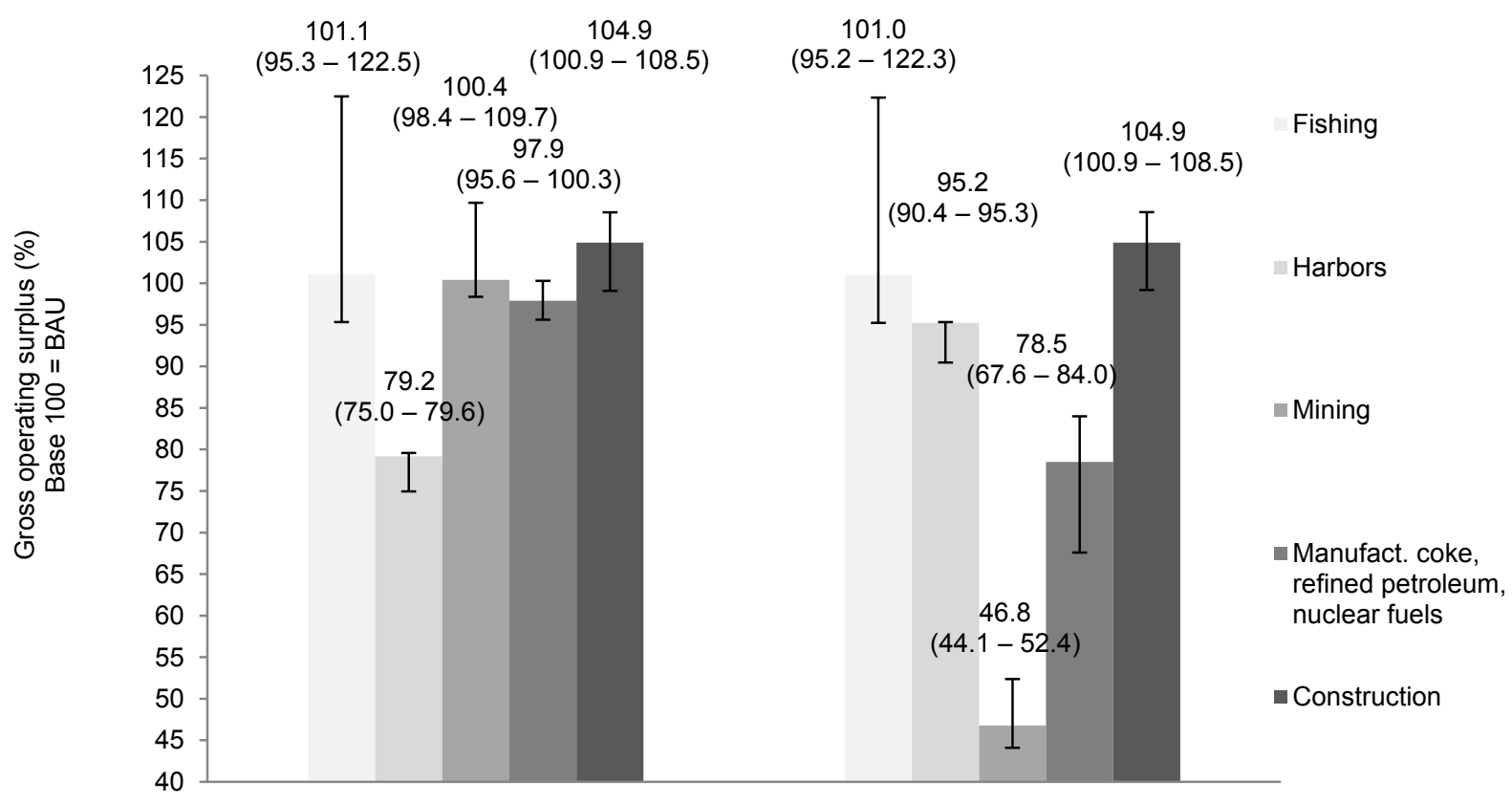

2015 (Restoration costs paid by harbors) 2015 (Restoration costs shared between sectors)

Figure 3. Sectorial impacts of nursery restoration scenarios in terms of gross operating surplus (20072015).

\subsection{Stakeholder participation and the risk of challenging the reliability of an I-O black-box:}

The use of the I-O model within a stakeholder participation process might cause difficulties because it can be seen as a black-box compared to modelling approaches such as System Dynamics, which is considered as more transparent. However, there is no guarantee that a system dynamics model will be more open than any other (Stave, 2002). It is just that promoting openness is generally considered good practice in system dynamics, that is to say using a model to structure the discussion within stakeholder 
participation process. There is no reason to imagine that I-O modelling could not also be transparent. I-O modelling is made of a number of equations that is considerably reduced compared to other economic models (e.g. Computable General Equilibrium models made of hundreds of equations). For instance, the ecological-economic model developed in this paper is made of a set of 32 equations. As a result, its main principles and equations could be quite easily explained to stakeholders. If it is properly explained, well documented and built in conjunction with stakeholders (for the regionalization and the integration of environmental data into the national Supply-Use table), the I-O model developed in this paper is simple enough to be understood by stakeholders and to be used within the participative process.

Nevertheless, it is true that stakeholders might lack the time to enter into detailed explanations on I-O principles and equations, leaving it a black-box for most of them. That could be a pretext for some stakeholder groups to challenge the results given by the model and deny their reliability (read Box 1). However, the architecture of the model (technical coefficients and linear relationships) has been validated for its economic part. It shows that most of the error percentages are quite low. It should make stakeholders more confident about the reliability of the model. The validation process begins with inserting into the model (in $\mathbf{F}^{\mathbf{d}} \mathbf{i}$ from eq. 1) values of final demand observed in 1999, 2005 and 2006. Then it compares the results given by the model, whose architecture is based on economic data from the reference year 2007, with observed data for the same three years. This validation process shows that in terms of total value added, total employment and GDP, the results given by the model differ from observed values by a percentage error that ranges from $-5 \%$ to $+17 \%$. This is quite a low range of error given that the technical coefficients are static and linear relationships are assumed between final demand and output production. At the sector level, errors on sectorial value added range between $-20 \%$ and $+30 \%$ (tested on 13 sectors; the lack of observed data did not allow us to test the 22 other sectors). Only the motor vehicle sector shows a high error range from $+22 \%$ to $+91 \%$. However, this error could be corrected by revising the regionalization operation of the national I-O tables carried out to build the regional model (read section 4). All these error percentages are included in the error bars of the graphs shown in Figure 1, 2 and 3 (except for the motor vehicle sector which is not shown on the graphs).

\section{Conclusion}

In this paper, we develop an ecological-economic I-O model to estimate the impacts of the restoration of half of the fish nurseries with high juvenile densities $\left(73.7 \mathrm{~km}^{2}\right)$ that have been largely destroyed between 1834 and 2004. Our results show that such a measure, applied on the basis of the precautionary principle advocated in the Marine Strategy Framework Directive (European Parliament and Council, 2008), can be implemented in the Seine estuary with only a slight decrease in macroeconomic indicators compared to a situation without restoration (BAU scenario). The amount of sole biomass generated by the restoration exceeds the BAU scenario by $44.2 \%$, while the GDP, the total gross operating surplus, the total compensation of employees, and the total employment are all below the BAU by $0.2 \%$. However, these results must be considered as partial. If all costs of nursery restoration were included in the model, a part of ecosystem services could not be assessed because appropriate data and knowledge do not exist yet. Only two ecosystem services are evaluated by the model. The first is life support for juvenile sole, an overfished species whose population is at risk in the Eastern channel (ICES, 2008). The second is the provisioning service of sole for human consumption, which is an important service provided to the economy, given the high commercial value of sole. If, without considering all the benefits from ecosystem services, our results show little negative macro-economic impact, extending the assessment to the five other ecosystem services mentioned in Section 6.2 would probably demonstrate that nursery restoration has positive macroeconomic impacts. The model is operational and ready for extension to these other services as soon as appropriate data becomes available.

The results also show that a vast nursery restoration programme generates significant economic impacts on the sector level rather than on the macro-economic one. This suggests that the restoration costs can be seen more as a problem of cost allocation than as a problem per se. In this perspective, the 
model helps to identify the sectors which would be the most vulnerable if the Polluter Pays Principle" were applied, such as recommended in the Marine Strategy Framework Directive. This concerns harbours, the mining sector and the sector of coke manufacturing, refined petroleum products \& nuclear fuels sector (Section 6.3). Identifying vulnerable sectors might help decision makers to adapt this principle and change the cost allocation rules, if they want to avoid a complete collapse of some economic sectors. For instance, indirect polluters such as the tertiary sector and final consumers (households) could participate in restoration costs, since both benefit from commodities transported on water.

Moreover, this paper shows possibilities to improve the holistic properties of I-O modelling, one of the two basic principles of Post-Normal Science and ICZM that is tested in this paper. This is achieved by extending the amount of categories of ecosystem services considered. Usually, I-O analyses only address the problem of sink (accumulation of pollutants emitted into the ecosystem) and provisioning services (provision of natural resources for human consumption). In this paper, we extend I-O modelling to supporting services (estuarine nurseries as a habitat for fish juveniles). Such extension is very important because supporting services are the most vital category of ecosystem services, since all other ecosystem services depend on them (Millennium Ecosystem Assessment, 2005; de Groot et al., 2002). Besides extending the number of ecosystem service categories, holistic properties are also ensured by the use of multiple indicators and units in our I-O model. This fulfils the recommendation from Post-Normal Science advocating the use of a diverse panel of indicators to capture the complexity of ecosystems and ensure holistic properties (Giampietro et al., 2006). Along with the use of recent developments in biology and hydro-sedimentology, this makes it possible to consider interdependencies between ecosystem services in I-O modelling, as recommended by Carpentier (1994) (Section 3.1). This also encounters the definition of holistic" from Gallopin et al. (2001) (Section 1).

If the advantage of holistic properties is a better understanding of the inherent complexity of ecosystems and to enlarge the amount of ecosystem service categories considered, the disadvantage is that great uncertainty is introduced into scientific analyses (Section 3.1). As recommended by PostNormal Science and ICZM, this uncertainty should be managed. To fulfil this recommendation, we apply the following strategy. Part of the uncertainty - the degree of precision - is handled through a sensitive analysis showing the range of values within which our results may vary, due to the relative indeterminacy on the model parameters (Section 6). This concerns the short to medium term uncertainty as to the capacity of estuarine nurseries to shelter sole juveniles (depending on sediment and water contamination - sink service), the nursery surface area that will remain (life support service), and the marine fish stock in the Eastern channel for human consumption (provisioning service). Another part of uncertainty - the degree of accuracy - is handled through the validation of the economic results given by the model based on economic data observed in the past. The discrepancy between observed data and the results given by the model is used as a measure of the uncertainty due to the architecture of the model. Another part of the uncertainty cannot be analysed through sensitivity analysis because it relates to parameters and variables that could not be inserted into the model. This problem concerns the five ecosystem services mentioned in Section 6.2 for which appropriate data do not yet exist. As a result, uncertainty remains on the interdependencies between these five ecosystem services and the economic system. Until data and knowledge are produced, this is typically the kind of issue for which final decision relies more on individual judgment and common sense than on scientific evidence. This shows the need for transparent inclusion of divergent public perspectives and value judgment in decision-making processes via stakeholder participation techniques (Giampietro et al., 2006; Stirling, 2006).

\section{Acknowledgements}

We are grateful to Garry McDonald from Market Economics Ltd. (New Zealand) for his help in I-O techniques. We are also much in debt to all the members of the GIP Seine-Aval for their comments, especially Axel Romania and Loïc Guezennec. We would like to thank Olivier Le Pape from the 
Agrocampus Ouest for the data on sole and nursery habitats, as well as Christophe Bessineton and Thomas Lecarpentier from the Maison de l'Estuaire, and Antoine Cuvilliez from the Université du Havre and Université de Rouen. We are also grateful to Michel Englert and Luc Avonds from the Federal Planning Bureau (Belgium) for their constructive comments, as well as to Aline Martin and Kate Weir for checking the English. We would like to thank Denis Bailly and Thomas Sawyer Hopkins, the scientific coordinators of the SPICOSA project, who inspired this research. We would also like to thank the four anonymous reviewers who helped to considerably improve this paper. This research was co-funded by Ifremer and the GIP Seine-Aval with a complementary grant from the Fonds David \& Alice Van Buuren and the Department of International Relations of the Université Libre de Bruxelles.

\section{References}

Ackerman, F., 2004. Priceless Benefits, Costly Mistakes: What's Wrong With Cost-Benefit Analysis? Post-autistic Econ. Rev. 25, $2-7$.

AESN-DIREN Haute-Normandie, 2004. Démarche prospective à l'horizon 2025 sur l'estuaire de la Seine. Annexes. France, pp. 129.

Ashford, N. A., 1981. Alternatives to cost-benefit analysis in regulatory decisions. Annuals of the New York Academy of Sciences, 363, 129-137.

Belfiore, S., 2000. Recent developments in coastal management in the European Union. Ocean \& Coastal management 43, 123-135.

Carpentier, C.L., 1994. Agriculture and the environment: an economic-ecological Input-Output Model of the Canadian economy. PhD at McGill University, Montreal, 121 pp.

Cumberland, J.H., 1966. A regional inter-industry model for the analysis of development objectives. Papers in Regional Science Association 17, 64-94.

Cuvilliez, A., Deloffre, J., Lafite, R., Bessineton, C., 2009. Morphological responses of an estuarine intertidal mudflat to constructions since 1978 to 2005: The Seine estuary (France). Geomorphology 104 (3-4), 165-174.

Daly, H.E., 1968. On Economics as a Life Science. Journal of Political Economy 76, 392 - 406.

de Groot, R.S., Wilson, M.A., Boumans, R.M.J., 2002. A typology for the classification, description and valuation of ecosystem functions, goods and services. Ecological Economics 41, 393-408.

European Parliament and Council, 2008. Directive 2008/56/EC of the European Parliament and of the Council of 17 June 2008 establishing a framework for community action in the field of marine environmental policy (Marine Strategy framework Directive).

European communities, 2009. Common implementation strategy for the water directive (2000/60/CEC). Guidance Document No 20. Guidance document on exemptions to the environmental objectives. European Communities, Luxemburg, 42 pp.

Eurostat, 2009. ESA 95 Supply Use and Input-Output tables. URL: http://epp.eurostat.ec.europa.eu/portal/page/portal/esa95 supply use input tables/data/workbook $\underline{\mathrm{s}}$

Federal Planning Bureau (FPB), 2008. Medium-Term prospects for the World Economy. Period 20082015. Van Brusselen, P. (Ed.), Belgium, 49 pp. 
Funtowicz, S.O., Ravetz, J.R., 1994. The worth of a songbird: ecological economics as a post-normal science. Ecological Economics 10 (3), 197-207.

Gallopin, G., Funtowicz, S., O'Connor, M., Ravetz, J., 2001. Science for the twenty-first century: from social contract to the scientific core. Int. Journal Social Science 168, 219-229.

Giampietro, M., Mayumi, K., Munda, G., 2006. Integrated assessment and energy analysis: Quality assurance in multi-criteria analysis of sustainability. Energy 31, 59-86.

Gobin, A., Jones, R., Kirkby, M., Campling, P., Govers, G., Kosmas, C., Gentile, A.R., 2004. Indicators for pan-European assessment and monitoring of soil erosion by water. Environmental Science and Policy 7, 25-38.

Hannon, B., 2001. Ecological pricing and economic efficiency. Ecological Economics 36, 19-30.

ICES. 2007. Report of the Working Group on the Assessment of Demersal Stocks in the North Sea and Skagerrak (WGNSSK), 5-14 September 2006, ICES Headquarters. ACFM 35, 1160 pp.

ICES, 2008. Report of the ICES Advisory Committee 2008. ICES Advice, 2008. Book 6. Denmark, $326 \mathrm{pp}$.

Ifremer, 1999. Etude des nourriceries de la Baie de Seine orientale et de l'estuaire de la Seine. Ifremer, Port-en-Bessin, France, 74 pp.

Ifremer, 2003. Conséquences économiques de l'évolution, de l'environnement dans l'estuaire de la Seine sur la pêche professionnelle. Rapport final du projet, Seine aval II. Ifremer, Brest, France, $177 \mathrm{pp}$.

Isard, W., 1968. Some notes on the linkage of the ecologic and economic systems. Regional science association: papers, XXII, Budapest conference.

Jin, D., Hoagland, P., Dalton, T.M., 2003. Linking economic and ecological models for a marine ecosystem. Ecological Economics 46, 367-/385.

Leontief, W.W., 1936. Quantitative input and output relations in the economic system of the United States. The review of economic statistics, 18 (3), 105-125.

Leontief, W.W., 1970. Environmental repercussions and the economic structure: an input-output approach. Review of Economics and Statistics LII (3), 261-271.

Lixon, B., Thomassin, P. J., Hamaide, B., 2008. Industrial output restriction and the Kyoto protocol: An input-output approach with application to Canada. Ecological Economics 68, 249-258.

Lutz, W., Sanderson, W., 2001: The end of world population growth. Nature, 412(6846), pp. 543-545.

Maréchal, K., 2007. The economics of climate change and the change of climate in economics. Energy Pol. 35, 5181-5194.

Maxim, L., Spangenberg, H. J., O'Connor, M., 2009. An analysis of risks for biodiversity under the DPSIR framework. Ecological Economics 69 (1), 12-23.

McDonald, G., 2005. Integrating Economics and Ecology: A systems Approach to Sustainability in the Auckland Region. PhD at Massey university, New Zealand, 597 pp. 
Meadows DH, Robinson JM. 1985. The Electronic Oracle: Computer Models and Social Decisions. John Wiley \& Sons Inc (Ed.), 462 pp.

MEDDAT, 2009. National and international transport. Data base received from the MEDDAT in June 2009.

Millennium Ecosystem Assessment, 2005. Ecosystems and Human Well-being: Synthesis. Island Press (Ed.), Washington, DC, 139 pp.

Miller, R.E., Blair, P.D., 2009. Input-output Analysis. Foundations and Extensions. Cambridge University press (Ed.), United-Kingdom, $750 \mathrm{pp}$.

Munda, G., 2004. Social multi-criteria evaluation: Methodological foundations and operational consequences. European journal of operational research 158, pp. 662-677.

Munda, G., Nijkamp, P., Rietveld, P., 1994. Qualitative multicriteria evaluation for environmental management. Ecological Economics 10, 97-112.

O'Hagan, A. M., Ballinger, R., 2009. Coastal governance in North West Europe: an assessment of approaches to the European stocktake. Marine policy 33, 912-922.

OECD, 2009. OECD Economic Outlook 86 Projection, summary of projections. Excel database. URL: www.oecd.org/dataoecd/18/26/2713584.xls

OFIMER, 2003. Pêche aquaculture. URL: http://wwz.ifremer.fr/envlit/region/haute normandie/activites/peche aquaculture

Port Autonome du Havre, 2000. Etude d'impact réglementaire du projet Port 2000. Résumé non technique. Dossier pour le comité consultatif de la réserve naturelle. Le Havre (Ed.), France, 101 pp.

Ravetz, J.R., 2006. Post-Normal Science and the complexity of transitions towards sustainability. Ecological Complexity 3 (4), Pp. 275-284.

Refsgaard, J.C., van der Sluijs, J.P., Brown, J., van der Keur, P., 2006. A framework for dealing with uncertainty due to model structure error. Advances in Water Resources 29 (11), 1586-1597.

Riddington, G., Gibson, H., Anderson, J., 2006. Comparison of Gravity Model, Survey and Location Quotient-based Local Area Tables and Multipliers. Regional Studies 40 (9), 1069 - 1081.

Rochette, S., Rivot, E., Morin, J., Mackinson, S., Riou, P., Le Pape, O., 2010. Effect of nursery habitat degradation on flatfish population renewal. Application to Solea solea in the eastern Channel (Western Europe). Journal of sea Research 64 (1-2), 34-44.

Shipman, B. and Stojanovic, T., 2007. Facts, Fictions, and Failures of Integrated Coastal Zone Management in Europe. Coastal Management, 35 (2), 375 - 398.

Sorensen, J., 2002. Baseline 2000 background report: the status of integrated coastal management as an international practice. Second iteration, 26 August.

Stave, A.K., 2002. Using system dynamics to improve public participation in environmental decisions. System Dynamics Review, 18 (2), 139-167.

Stirling, A., 2001. Science and precaution in the appraisal of electricity supply options. Journal of Hazardous Materials 86, 55-75. 
Stirling, A., 2006. Analysis, participation and power: justification and closure in participatory multicriteria analysis. Land Use Policy 23, 95-107.

Stojanovic, T.A., Ballinger, R.C., 2009. Integrated coastal management: a comparative analysis of four UK initiatives. Applied geography 29, 49-62.

van den Bergh, J.C.J.M., Nijkamp, P., 1991. Operationalizing sustainable development: dynamic ecological economic models. Ecological Economics 4, 11-23.

van den Bergh, J.C.J.M., 2000. Themes, Approaches, and Differences with Environmental Economics. Discussion Paper TI 2000-080/3, Tinbergen Institute, Amsterdam, The Netherlands, 25 pp.

Victor, A.P., 1972. Pollution: economy and environment. Georges Allen \& Unwin Ltd. (Eds.), Great Britain, 247 pp. 